Published in final edited form as:

Doc Ophthalmol. 2007 November ; 115(3): 145-153. doi:10.1007/s10633-007-9059-8.

\title{
The mouse pattern electroretinogram
}

\author{
Vittorio Porciatti \\ Bascom Palmer Eye Institute, University of Miami Miller School of Medicine, Miami, FL 33136, USA \\ Vittorio Porciatti: vporciatti@med.miami.edu
}

\begin{abstract}
Mouse models of optic nerve disease such as glaucoma, optic neuritis, ischemic optic neuropathy, and mitochondrial optic neuropathy are being developed at increasing rate to investigate specific pathophysiological mechanisms and the effect of neuroprotective treatments. The use of these models may be greatly enhanced by the availability of non-invasive methods able to monitor retinal ganglion cell (RGC) function longitudinally such as the Pattern Electroretinogram (PERG). While the use of the PERG as a tool to probe inner retina function in mammals is known since 25 years, relatively less information is available for the mouse. Here, the PERG technique and the main applications in the mouse are reviewed.
\end{abstract}

\section{Keywords}

Mouse; Pattern electroretinogram; Retinal ganglion cells; Mouse models

\section{The Pattern Electroretinogram (PERG)}

The Pattern Electroretinogram (PERG) is a particular kind of ERG obtained in response to contrast modulation of patterned visual stimuli at constant mean luminance-typically contrast-reversing gratings or checkerboards-whose characteristics are fundamentally different from those of the traditional ERG in response to diffuse flashes of light.

The idea of stripe alternation originated in Lorrin Riggs' laboratory, [1] and the technique was used as a method to obtain focal ERGs free from stray light as well as to obtain objective evidence on trichromatic color function. Later on, pattern alternation was widely adopted to the study of human VEPs (reviewed in [2]). For many years, the retinal origin of the PERG was considered equivalent to that of the non-patterned ERG. In 1981, Lamberto Maffei and Adriana Fiorentini [3] demonstrated that the main generator source(s) of the cat's PERG were located in the ganglion cell layer of the retina. Cutting the optic nerve intracranially caused a retrograde degeneration of retinal ganglion cells (RGCs) over several months; this effect was accompanied by a loss of the PERG over a similar span of time. Outer retinal function (flicker ERG) remained normal throughout the experiment. This experiment generated enormous interest in clinical as well as experimental laboratories, since the PERG represented the only known way to access the activity of RGCs directly [4,5]. A vast PERG literature developed in the last 20 years. In 2000, ISCEV proposed basic guidelines for the clinical application of the PERG [6]. The PERG is still the object of investigation using luminance-contrast to simplify the protocol [7] and to better understand underlying response mechanisms [8,9]. Patterns made of chromatic-contrast stimuli are also used to isolate color-opponent RGC subpopulations and identify their vulnerability in disease [10-16]. 


\section{Retinal generators of the PERG}

The pattern stimulus consists of black-white elements of equal areas whose luminances increase and decrease in time (flicker) at a given frequency $\mathrm{F}_{\mathrm{Hz}}$ (Fig. 1A). Adjacent elements flicker in counterphase, so that the overall stimulus luminance remains constant. At the retinal level, flickering pattern elements generate local flicker ERGs at frequency $\mathrm{F}_{\mathrm{Hz}}$. Because adjacent pattern elements generate local flicker ERGs $180^{\circ}$ out of phase, these are summed and canceled at the recording corneal electrode. An ERG is recordable in response to pattern reversal because additional, non-linear ERG components are generated (mainly at frequency $2 \mathrm{~F}_{\mathrm{Hz}}$ : corresponding to the contrast-reversal rate) that are in-phase and do not cancel at the electrode. This is what constitutes the PERG. The main generators of local flicker ERGs at $\mathrm{F}_{\mathrm{Hz}}$ are likely the photoreceptors that have approximately linear behavior, whereas the PERG generators at $2 \mathrm{~F}_{\mathrm{Hz}}$ are likely post-receptoral elements with center-surround receptive field organization and non-linear behavior (discussed in [17]). Note in Fig. 1A that pattern elements of adequate size generate lateral inhibition via horizontal cells; differential center-surround activation of the RGC den-dritic field occurs for either period of the pattern-reversal. By contrast, when the entire stimulus field is modulated in luminance at frequency $\mathrm{F}_{\mathrm{Hz}}$ (Fig. 1B) local flicker ERGs at frequency $\mathrm{F}_{\mathrm{Hz}}$ are in-phase and sum at the electrode. Different from pattern-reversal, uniform field flicker generates little differential center-surround activation of the RGC receptive field. Thus, uniform field flicker is dominated by outer retina activity, whereas the PERG is dominated by inner retina activity. Outer retina activity is necessary for the PERG generation but it is not apparent in the PERG waveform because of cancellation at the electrode.

Since RGCs have receptive fields with strong center-surround antagonism, these seem to be the best candidates for PERG generation. RGCs are expected to be maximally activated by pattern elements whose dimensions match the average size of the RGC receptive field center. In keeping with this prediction, the PERG amplitude displays a maximum at a specific spatial frequency that approximately corresponds to the average RGC receptive field size in human $[18,19]$ as well as mouse $[20,21]$. In addition, for a given retinal eccentricity and stimulus area, the PERG amplitude to the peak spatial frequency is linearly proportional to the expected volume of RGCs [22].

RGC activity is indeed necessary for PERG generation, since RGC retrograde degeneration after optic nerve transection abolishes the response; the conventional flash-ERG, which originates in the outer retina, is little or not affected. This crucial experiment has been successfully performed in several mammals including cat, [3,23] monkey, [11,24] rat, [25, 26] and mouse [27-29]. In the rat, the site of lesion of the optic nerve affects the time of disappearance of the PERG [26]. The PERG takes longer to disappear and RGCs take longer to degenerate after an intracranial section compared to an intraorbital section. An inner retina origin for the mammalian PERG has been also confirmed by current-source analysis of intraretinal recordings [30,31]. In birds, PERG generators appear to have a pre-ganglionic origin, since the response is unaffected when RGCs are axotomized [32,33].

In mammals, PERG generation requires physiological integrity of anatomically present RGCs. The PERG amplitude can be reversibly reduced, although not abolished, by intravitreal injections of tetrodotoxin which block $\mathrm{Na}^{+}$dependent spiking activity in the inner retina $[8$, 34]. Short-term, moderate elevation of the intraocular pressure (IOP) reversibly reduces the PERG amplitude while leaving the flash-ERG unaltered [35,36]. A reduction of PERG amplitude may therefore reflect both the reduced activity of dysfunctional RGCs and the lack of activity of lost RGCs. 
In sum, strong evidence supports the view that functional RGCs are necessary to generate the PERG, whereas less is known about what aspects of RGC activity relate to the response. While a TTX-dependent component suggests that RGC-axon spiking activity plays a role in PERG generation, slow electrical activity generated at the level of RGC dendrites, or electrical activity in the inner retina circuitry impinging on RGCs cannot be excluded. Finally, a Muller cell component in the PERG generation cannot be excluded, since Muller cells can passively generate electric currents in response to extracellular modulation of $\mathrm{K}^{+}$ions produced by active retinal neurons $[37,38]$.

Thus, the PERG represents an important tool to monitor the onset and the progression of RGC dysfunction in mouse models of optic nerve disease that are being developed at ever increasing rate. These include a variety of blinding disorders such as glaucoma, optic neuritis, ischemic optic neuropathy, and mitochondrial optic neuropathy [39]. Since the PERG reflects inner retina activity under light-adaptation, the PERG should be used in combination with a traditional light-adapted luminance ERG to have an index of outer retina function under analogous conditions [21]. The nature of the PERG (focal, cone-driven, post-receptoral) implies that the level of signal is much smaller than the traditional ERG. However, robust averaging (1800 sweeps) produces PERGs with a signal-to-noise ratio on the order of 10:1 and with a test-retest variability of about $30 \%$, [21] which is comparable to that of the traditional ERG [40].

\section{Methods for PERG recording}

An optimized protocol for mouse PERG recording has been recently described [21]. In brief, mice are anesthetized with I.P. injections $(0.5-0.7 \mathrm{ml} / \mathrm{Kg})$ of a mixture of Ketamine, $42.8 \mathrm{mg} /$ $\mathrm{ml}$, Xylazine, $8.6 \mathrm{mg} / \mathrm{ml}$, and Acepromazine, $1.4 \mathrm{mg} / \mathrm{ml}$. Mice are gently restrained using a mouth bite bar and a nose holder that allows unobstructed vision, and kept at a constant body temperature of $37.0^{\circ} \mathrm{C}$ using a feedback-controlled heating pad. Under these conditions the eyes of mice are naturally wide open and in a stable position, with pupils pointing laterally and upward. The recording electrode is a thin $(0.25 \mathrm{~mm}$ diameter) silver wire configured to a semicircular loop of $2 \mathrm{~mm}$ radius, which is gently placed on the corneal surface in such a way as to encircle the undilated pupil without interfering with vision (Fig. 2). Electrode positioning entails minimal corneal stimulation, which might otherwise induce cataract [41,42] and preclude further PERG testing. Reference and ground electrodes are small stainless steel needles inserted in the skin of the back of the head and the back of the body, respectively. Instillations of BSS drops every $30 \mathrm{~min}$ are sufficient to maintain the cornea and lens in excellent condition for many hours. Pattern stimuli consist of horizontal bars of variable spatial frequencies and contrast that alternate at different temporal frequency. Stimuli are displayed on a TV monitor whose center is aligned with the projection of the pupil and presented from a short distance (typically $20 \mathrm{~cm}$ ) to stimulate a large retinal area (typically $50-60^{\circ}$ ) centered on the optic disk (Fig. 2). Eyes are not refracted for the viewing distance since the mouse eye has a large depth of focus due to the pinhole pupil [43,44] PERGs [27] and Pattern VEPs [45] are not modified by trial lenses of \pm 10 spherical diopters placed before the eyes. Compared to the traditional ERG, the PERG has an amplitude smaller by a factor of about 100. Therefore, robust averaging is needed to isolate the response from background noise. Under conditions that maximize PERG amplitude (spatial frequency 0.05 cycles/deg, temporal frequency $1 \mathrm{~Hz}$, contrast 100\%), and substantial averaging (1800 sweeps), the PERG signal to noise ratio is of the order of 10:1, and the test-retest variability is of the order of 30\% [21]. These parameters represent adequate conditions for monitoring disease progression in mouse models of optic nerve disorders. 


\section{PERG correlates of visual behaviors}

By recording the PERG in response to increasing spatial frequency, decreasing contrast, or increasing contrast reversal rate, it is possible to obtain estimates of the mouse retinal resolution (acuity), [27,46] contrast threshold, [27,47] and temporal resolution [48]. PERG acuity has been previously shown to be correlated with behavioral acuity in the cat, [49] and rat; [25] PERG acuity also correlates well with VEP acuity in human [50], [51] as well as monkey [52]. Visual thresholds determined at the retinal level with the PERG in the mouse have a counterpart in corresponding measures of visual acuity and contrast sensitivity determined with VEPs, [45] operant psychophysical behavior, [53-55] and passive optomotor response [56, 57] By combining PERG measures with VEP, optomotor response or psychophysical visual behavior, it is possible to evaluate the relative contribution of retinal and postretinal stages to a particular disease or condition.

\section{Examples of PERG applications in mice}

\section{Development of mouse PERG acuity}

Around eye opening (P14-15) the PERG acuity of the C57BL/6J mouse is of the order of 0.2 cycles/deg and matures during the next two weeks to reach the adult acuity ( 0.6 cycles/deg) by about 1 month of age (Fig. 3). PERG acuity develops postnatally [58,59] in parallel with visual acuity determined with either VEPs [60] or optomotor response [56].

\section{Role of developmental spontaneous activity}

In the mammalian visual system the formation of eye-specific layers at the thalamic level depends on retinal waves of spontaneous activity, [61] which rely on nicotinic acetylcholine receptor activation [62]. In mutant mice lacking the $\beta 2$ subunit of the neuronal nicotinic receptor, [63] but not in mice lacking the $\alpha 4$ subunit, retinofugal projections do not form normal eye-specific layers in the dorso-lateral geniculate nucleus $[46,64]$. $\beta 2-/-$ mice show an expansion of the binocular subfield of the primary visual cortex and a decrease in visual acuity at the cortical level (VEP) [46]. The PERG acuity however, is identical in $\beta 2-/-$ and wild type mice [46]. In addition, detailed anatomical analysis of different RGC classes does not reveal significant differences between wild-type and $\beta 2-/-$ animals [65]. These results indicate that cholinergic-mediated activity in the developing retina is not required for the normal postnatal development of RGCs, but is necessary for the anatomical and functional development of the post-retinal visual system.

\section{Role of developmental cell death}

The Bcl-2 protein is a potent inhibitor of apoptotic cell death. Transgenic mice have been generated with overexpression of the human bcl-2 gene in RGCs and in most neurons of the CNS [66]. As a result of inhibition of apoptotic cell death during development, adult Bcl-2 overexpressing mice have 2.6 times more RGCs and optic nerve fibers than normal, and have larger brains [67]. Despite marked neuronal redundancy in the visual pathway, the PERG acuity of the bcl-2 overexpressing mouse is normal [27] The cortical (VEP) visual acuity and contrast threshold [47] are also normal; the behavioral visual acuity is normal as well [54]. A detailed anatomical study of the bcl-2 transgenic mouse retina [68] indicates that a compensatory growth of axonal arborizations of bipolar cells ultimately results in an increased divergence upon RGCs, thus neutralizing the effect of their higher density. At the cortical level, neuronal redundancy causes expansion of the brain, which keeps neuronal density in the normal range [47]. To account for brain expansion, the cortical representation of the visual co-ordinates (i.e. the vertical meridian) is shifted laterally [47]. 


\section{Survival of RGCs after optic nerve lesion}

In adult mice overexpressing bcl-2 the great majority of RGCs survive for a long time after intracranial optic nerve section, [67] and the PERG is spared [27-29]. This suggests that neuroprotective strategies aimed at targeting the apoptotic cascade at mitochondrial levels may successfully rescue from death a high number of RGCs with normal physiological response. Mice deficient in BCL2-associated X protein (BAX) can be also used to investigate the role of BAX-mediated cell death in optic nerve lesions. BAX deficiency protects RGCs after axon injury by optic nerve crush [69]. BAX deficiency in DBA/2J mice with spontaneous glaucoma (see below) protect RGCs from death [69]. It remains to be established whether protected RGCs maintain normal function.

\section{Progressive PERG loss in glaucomatous mice}

The DBA/2J mouse is a well established model of spontaneous glaucoma. Recessive mutations in two genes, Gpnmb and Tyrp1, cause iris atrophy and pigment dispersion [70]. The iris disease is apparent at 6 months and progresses with age, resulting in elevated IOP [71]. Young (2-3 month-old) DBA/2J mice have normal IOP, normal PERG, and normal histological appearance of RGCs and optic nerves. Glaucoma damage in the optic nerve is apparent in about $50 \%$ of eyes by $10-11$ months of age, and in about $90 \%$ of eyes by 18 months [71]. At 8 months of age, when the PERG amplitude has lost about $50 \%$ of its baseline (2 month-old) level, [72] the optic nerves are histologically intact [71]. Between 10 and 11 months of age, when only $50 \%$ of the optic nerves show signs of degeneration, the PERG amplitude is at or close to the noise level (about $85 \%$ smaller than the baseline level) in $100 \%$ of mice [21]. The lightadapted flash-ERG displays only minor changes, $[21,73]$ and the outer retina is histologically intact [74]. Altogether, these results suggest that in DBA/2J mice inner retina dysfunction precedes anatomical axon loss.

The non-invasive nature of the PERG allows serial recordings as a function of changing conditions (e.g., age, IOP levels). Recently, we have been able to characterize the natural history of RGC dysfunction and its relationship with IOP in a 12-month longitudinal study of $\mathrm{BDA} / 2 \mathrm{~J}$ mice [72]. On average, the IOP increases from $15 \mathrm{~mm} \mathrm{Hg}$ to $20 \mathrm{~mm} \mathrm{Hg}$ between 2 and 6 months; after 6 months the IOP displays a steeper increase and tends to level off by 11 months at a value of about $30 \mathrm{~mm} \mathrm{Hg}$ [72]. After 3 months, the PERG amplitude decreases progressively with age to reach the noise level at about 10-11 months [72]. Histological analysis of eyes with abolished PERG shows that the retinal nerve fiber layer has lost only about $40 \%$ of the normal thickness. Between 2 and 11 months the cone-flash ERG does not show significant changes [72]. However, at about 13 months of age the FERG is also significantly reduced in amplitude by $38 \%$ [21]. We were also able to characterize the changes in IOP and PERG that occur when DBA/2J mice are put in a head-down $\left(60^{\circ}\right)$ body position [75]. Postural changes cause substantial $(+30-35 \%)$, reversible IOP increases in DBA/2J mice of different ages (3-10 months) [76]. Postural changes also cause PERG amplitude reduction that are strongly age-dependent ( 3 month-old: no change; 5 month-old: $-48 \%$; 10 month-old: $-67 \%)[76]$.

Taken together, these results suggest that DBA/2J mice develop an IOP-dependent, progressive functional damage in the inner retina (abnormal PERG) but not in the outer retina (normal flash-ERG) that seems to precede anatomical damage of the optic nerve.

\section{Advantages and limitations of the PERG technique}

The PERG appears to represent a powerful tool to characterize the visual phenotype of mice with different genotypes, as well as that of mouse models of optic nerve diseases. Its noninvasive nature allows serial recordings to evaluate longitudinal changes of normal and 
abnormal RGC activity, as well as their response to either modulation of stress factors or neuroprotective treatments. The PERG may represent the necessary functional endpoint for neuroprotection studies, since residual/spared RGCs may not be functional. Further studies are needed to better understand what aspects of RGC activity relate to the response.

The main limitation of the PERG technique is that it requires integrity of the eye optics to be properly recorded. Cataracts may develop in experimental mouse eyes as a result of drugs, cold, anoxia, stress, and dehydration. Careful manipulation of experimental mice is needed to prevent cataract formation. Another potential shortcoming is that the PERG is a relatively small signal compared to the traditional ERG. Robust averaging, however, produces PERGs with good signal-to-noise ratio and with a test-retest variability comparable to that of the traditional ERG.

\section{Acknowledgments}

NIH RO3 EY016322, NIH RO1 EY014957, NIH center grant P30-EY14801, unrestricted grant to the University of Miami from Research to Prevent Blindness, Inc.

\section{References}

1. Riggs LA, Johnson EP, Schick AML. Electrical responses of the human eye to moving stimulus pattern. Science 1964;144:567-568. [PubMed: 17836392]

2. Riggs LA. Electroretinography. Vision Res 1986;26(9):1443-1459. [PubMed: 3303668]

3. Maffei L, Fiorentini A. Electroretinographic responses to alternating gratings before and after section of the optic nerve. Science 1981;211(4485):953-955. [PubMed: 7466369]

4. Regan, D. Evoked potentials and evoked magnetic fields in science and medicine. Elsevier; New York: 1989. Human brain electrophysiology.

5. Zrenner, E. The physiological basis of the pattern electroretinogram. In: Osborne, N.; Chader, G., editors. Progress in retinal research. Vol. 9. Pergamon Press; Oxford: 1990.

6. Bach M, Hawlina M, Holder GE, et al. Standard for pattern electroretinography. International Society for Clinical Electrophysiology of Vision. Doc Ophthalmol 2000;101(1):11-18. [PubMed: 11128964]

7. Porciatti V, Ventura LM. Normative data for a user-friendly paradigm for pattern electroretinogram recording. Ophthalmology 2004;111(1):161-168. [PubMed: 14711729]

8. Viswanathan S, Frishman LJ, Robson JG. The uniform field and pattern ERG in macaques with experimental glaucoma: removal of spiking activity. Invest Ophthalmol Vis Sci 2000;41(9):27972810. [PubMed: 10937600]

9. Porciatti V, Sorokac N, Buchser W. Habituation of retinal ganglion cell activity in response to steady state pattern visual stimuli in normal subjects. Invest Ophthalmol Vis Sci 2005;46(4):1296-1302. [PubMed: 15790894]

10. Korth M, Rix R. The pattern ERG in response to colored stimuli. Doc Ophthalmol 1987;65(1):7177. [PubMed: 3665705]

11. Morrone C, Fiorentini A, Bisti S, et al. Pattern-reversal electroretinogram in response to chromatic stimuli: II. Monkey. Vis Neurosci 1994;11(5):873-884. [PubMed: 7947401]

12. Morrone C, Porciatti V, Fiorentini A, Burr DC. Pattern-reversal electroretinogram in response to chromatic stimuli: I. Humans. Vis Neurosci 1994;11(5):861-871. [PubMed: 7947400]

13. Porciatti V, Morrone MC, Fiorentini A, et al. The pattern electroretinogram in response to colour contrast in man and monkey. Int J Psychophysiol 1994;16(2-3):185-189. [PubMed: 8089037]

14. Porciatti V, Sartucci F. Retinal and cortical evoked responses to chromatic contrast stimuli. Specific losses in both eyes of patients with multiple sclerosis and unilateral optic neuritis. Brain 1996;119 (Pt 3):723-740. [PubMed: 8673486]

15. Porciatti V, Di Bartolo E, Nardi N, Fiorentini A. Responses to chromatic and luminance contrast in glaucoma: a psychophysical and electrophysiological study. Vision Res 1997;37(14):1975-1987. [PubMed: 9274782] 
16. Sartucci F, Orlandi G, Bonuccelli U, et al. Chromatic pattern-reversal electroretinograms (ChPERGs) are spared in multiple system atrophy compared with Parkinson's disease. Neurol Sci 2006;26(6): 395-401. [PubMed: 16601931]

17. Baker CL Jr, Hess RF. Linear and nonlinear components of human electroretinogram. J Neurophysiol 1984;51(5):952-967. [PubMed: 6726320]

18. Hess RF, Baker CL Jr. Human pattern-evoked electroretinogram. J Neurophysiol 1984;51(5):939_ 951. [PubMed: 6726319]

19. Drasdo N, Thompson DA, Thompson CM, Edwards L. Complementary components and local variations of the pattern electroretinogram. Invest Ophthalmol Vis Sci 1987;28(1):158-162. [PubMed: 3804646]

20. Stone C, Pinto LH. Response properties of ganglion cells in the isolated mouse retina. Vis Neurosci 1993;10(1):31-39. [PubMed: 8424927]

21. Porciatti V, Saleh M, Nagaraju M. The pattern electroretinogram as a tool to monitor progressive retinal ganglion cell dysfunction in the DBA/2J mouse model of glaucoma. Invest Ophthalmol 2007;48(2):745-751.

22. Drasdo N, Thompson DA, Arden GB. A comparison of pattern ERG amplitudes and nuclear layer thickness in different zones of the retina. Clin Vision Sciences 1990;5(4):415-420.

23. Hollander H, Bisti S, Maffei L, Hebel R. Electroretinographic responses and retrograde changes of retinal morphology after intracranial optic nerve section. A quantitative analysis in the cat. Exp Brain Res 1984;55(3):483-493. [PubMed: 6468554]

24. Maffei L, Fiorentini A, Bisti S, Hollander H. Pattern ERG in the monkey after section of the optic nerve. Exp Brain Res 1985;59(2):423-425. [PubMed: 4029317]

25. Berardi N, Domenici L, Gravina A, Maffei L. Pattern ERG in rats following section of the optic nerve. Exp Brain Res 1990;79(3):539-546. [PubMed: 2340873]

26. Domenici L, Gravina A, Berardi N, Maffei L. Different effects of intracranial and intraorbital section of the optic nerve on the functional responses of rat retinal ganglion cells. Exp Brain Res 1991;86 (3):579-584. [PubMed: 1761091]

27. Porciatti V, Pizzorusso T, Cenni MC, Maffei L. The visual response of retinal ganglion cells is not altered by optic nerve transection in transgenic mice overexpressing Bcl-2. Proc Natl Acad Sci USA 1996;93(25):14955-14959. [PubMed: 8962163]

28. Chierzi S, Cenni MC, Maffei L, et al. Protection or retinal ganglion cells and preservation of function after optic nerve lesion in bcl-2 transgenic mice. Vision Res 1998;38:1537-1543. [PubMed: 9667018]

29. Ratto GM, Bonfanti L, Cenni MC, et al. Retinal ganglion cell anatomy and physiology after section of the optic nerve in mice overexpressing bcl-2. Adv Neurol 1997;72:87-94. [PubMed: 8993687]

30. Sieving PA, Steinberg RH. Proximal retinal contribution to the intraretinal 8-Hz pattern ERG of cat. J Neurophysiol 1987;57(1):104-120. [PubMed: 3559667]

31. Baker CL Jr, Hess RR, Olsen BT, Zrenner E. Current source density analysis of linear and non-linear components of the primate electroretinogram. J Physiol 1988;407:155-176. [PubMed: 3256615]

32. Bagnoli P, Porciatti V, Francesconi W, Barsellotti R. Pigeon pattern electroretinogram: a response unaffected by chronic section of the optic nerve. Exp Brain Res 1984;55(2):253-262. [PubMed: 6745365]

33. Blondeau P, Lamarche J, Lafond G, Brunette JR. Pattern electroretinogram and optic nerve section in pigeons. Curr Eye Res 1987;6(6):747-756. [PubMed: 3608564]

34. Trimarchi C, Biral G, Domenici L, et al. The Flash-and pattern electroretinogram generators in the cat: a pharmacological approach. Clin Vision Sci 1990;6:19-24.

35. Siliprandi R, Bucci MG, Canella R, Carmignoto G. Flash and pattern electroretinograms during and after acute intraocular pressure elevation in cats. Invest Ophthalmol Vis Sci 1988;29(4):558-565. [PubMed: 3356513]

36. Feghali JG, Jin JC, Odom JV. Effect of short-term intraocular pressure elevation on the rabbit electroretinogram. Invest Ophthalmol Vis Sci 1991;32(8):2184-2189. [PubMed: 2071332]

37. Kline RP, Ripps H, Dowling JE. Generation of b-wave currents in the skate retina. Proc Natl Acad Sci USA 1978;75(11):5727-5731. [PubMed: 281719] 
38. Frishman LJ, Yamamoto F, Bogucka J, Steinberg RH. Light-evoked changes in [K+]o in proximal portion of light-adapted cat retina. J Neurophysiol 1992;67(5):1201-1212. [PubMed: 1317916]

39. Levkovitch-Verbin H. Animal models of optic nerve diseases. Eye 2004;18(11):1066-1074. [PubMed: 15534591]

40. Grover S, Fishman GA, Birch DG, et al. Variability of full-field electroretinogram responses in subjects without diffuse photoreceptor cell disease. Ophthalmology 2003;110(6):1159-1163. [PubMed: 12799241]

41. Fraunfelder FT, Burns RP. Acute reversible lens opacity: caused by drugs, cold, anoxia, asphyxia, stress, death and dehydration. Exp Eye Res 1970;10(1):19-30. [PubMed: 5456775]

42. Ridder W 3rd, Nusinowitz S, Heckenlively JR. Causes of cataract development in anesthetized mice. Exp Eye Res 2002;75(3):365-370. [PubMed: 12384099]

43. Remtulla S, Hallett PE. A schematic eye for the mouse, and comparisons with the rat. Vision Res 1985;25(1):21-31. [PubMed: 3984214]

44. Schmucker C, Schaeffel F. A paraxial schematic eye model for the growing C57BL/6 mouse. Vision Res 2004;44(16):1857-1867. [PubMed: 15145680]

45. Porciatti V, Pizzorusso T, Maffei L. The visual physiology of the wild type mouse determined with pattern VEPs. Vision Res 1999;39(18):3071-3081. [PubMed: 10664805]

46. Rossi FM, Pizzorusso T, Porciatti V, et al. Requirement of the nicotinic acetylcholine receptor beta 2 subunit for the anatomical and functional development of the visual system. Proc Natl Acad Sci USA 2001;98(11):6453-6458. [PubMed: 11344259]

47. Porciatti V, Pizzorusso T, Maffei L. Vision in mice with neuronal redundancy due to inhibition of developmental cell death. Vis Neurosci 1999;16(4):721-726. [PubMed: 10431920]

48. Porciatti V, Falsini B. Physiological properties of the mouse pattern Electroretinogram. ARVO. 2003\#2705

49. Maffei L, Fiorentini A. Electroretinographic responses to alternating gratings in the cat. Exp Brain Res 1982;48(3):327-334. [PubMed: 7151927]

50. Fiorentini A, Pirchio M, Sandini G. Development of retinal acuity in infants evaluated with pattern electroretinogram. Hum Neurobiol 1984;3(2):93-95. [PubMed: 6746336]

51. Birch DG, Anderson JL. Standardized full-field electroretinography. Normal values and their variation with age. Arch Ophthalmol 1992;110(11):1571-1576. [PubMed: 1444914]

52. Ver Hoeve JN, Danilov YP, Kim CB, Spear PD. VEP and PERG acuity in anesthetized young adult rhesus monkeys. Vis Neurosci 1999;16(4):607-617. [PubMed: 10431910]

53. Sinex DG, Burdette LJ, Pearlman AL. A psychophysical investigation of spatial vision in the normal and reeler mutant mouse. Vision Res 1979;19(8):853-857. [PubMed: 516456]

54. Gianfranceschi L, Fiorentini A, Maffei L. Behavioural visual acuity of wild type and bcl 2 transgenic mouse. Vision Res 1999;39(3):569-574. [PubMed: 10341985]

55. Prusky GT, Douglas RM. Characterization of mouse cortical spatial vision. Vision Res 2004;44(28): 3411-3418. [PubMed: 15536009]

56. Prusky GT, Alam NM, Beekman S, Douglas RM. Rapid quantification of adult and developing mouse spatial vision using a virtual optomotor system. Invest Ophthalmol Vis Sci 2004;45(12):4611-4616. [PubMed: 15557474]

57. Schmucker C, Seeliger M, Humphries P, et al. Grating acuity at different luminances in wild-type mice and in mice lacking rod or cone function. Invest Ophthalmol Vis Sci 2005;46(1):398-407. [PubMed: 15623801]

58. Porciatti V, Falsini B. Maturation of flash-cone ERG and pattern ERG in the mouse. ARVO. 2000abstract \# 500

59. Porciatti V, Pizzorusso T, Maffei L. Electrophysiology of the postreceptoral visual pathway in mice. Doc Ophthalmol 2002;104(1):69-82. [PubMed: 11949810]

60. Huang ZJ, Kirkwood A, Pizzorusso T, et al. BDNF regulates the maturation of inhibition and the critical period of plasticity in mouse visual cortex. Cell 1999;98(6):739-755. [PubMed: 10499792]

61. Wong RO. Retinal waves and visual system development. Annu Rev Neurosci 1999;22:29-47. [PubMed: 10202531] 
62. Feller MB, Wellis DP, Stellwagen D, et al. Requirement for cholinergic synaptic transmission in the propagation of spontaneous retinal waves. Science 1996;272(5265):1182-1187. [PubMed: 8638165]

63. Picciotto MR, Zoli M, Lena $\mathrm{C}$, et al. Abnormal avoidance learning in mice lacking functional highaffinity nicotine receptor in the brain. Nature 1995;374(6517):65-67. [PubMed: 7870173]

64. Muir-Robinson G, Hwang BJ, Feller MB. Retino-geniculate axons undergo eye-specific segregation in the absence of eye-specific layers. J Neurosci 2002;22(13):5259-5264. [PubMed: 12097474]

65. Van der List DA, Coombs JL, Chalupa LM. Normal development of retinal ganglion cell morphological properties in mice lacking the beta2 subunit of the nicotinic acetylcholine receptor. ARVO. 2006abstract \# 3313

66. Martinou JC, Dubois-Dauphin M, Staple JK, et al. Overexpression of bcl-2 in transgenic mice protects neurons from naturally occurring cell death and experimental ischemia. Neuron 1994;13(4):10171030. [PubMed: 7946326]

67. Cenni MC, Bonfanti L, Martinou J-C, et al. Long-term survival of retinal ganglion cells following optic nerve section in adult I bcl-2 transgenic mice. Eur J Neurosci 1996;8:1735-1745. [PubMed: 8921264]

68. Strettoi E, Volpini M. Retinal organization in the bcl-2-overexpressing transgenic mouse. J Comp Neurol 2002;446(1):1-10. [PubMed: 11920715]

69. Libby RT, Li Y, Savinova OV, et al. Susceptibility to neurodegeneration in a glaucoma is modified by Bax gene dosage. PLoS Genet 2005;1(1):17-26. [PubMed: 16103918]

70. John SW, Smith RS, Savinova OV, et al. Essential iris atrophy, pigment dispersion, and glaucoma in DBA/2J mice. Invest Ophthalmol Vis Sci 1998;39(6):951-962. [PubMed: 9579474]

71. Libby RT, Anderson MG, Pang IH, et al. Inherited glaucoma in DBA/2J mice: pertinent disease features for studying the neurodegeneration. Vis Neurosci 2005;22(5):637-648. [PubMed: 16332275]

72. Saleh M, Nagaraju M, Porciatti V. The natural history of retinal ganglion cells and its relationship with IOP in DBA/2J mice. ARVO. 2007\#210

73. Libby RT, Porciatti V, Tapia M, et al. Perg analysis detects physiological dysfunction prior to ganglion cell loss In DBA/2J Glaucoma. ARVO. 2006E-abstract \# 4005

74. Jakobs TC, Libby RT, Ben Y, et al. Retinal ganglion cell degeneration is topological but not cell type specific in DBA/2J mice. J Cell Biol 2005;171(2):313-325. [PubMed: 16247030]

75. Aihara M, Lindsey JD, Weinreb RN. Episcleral venous pressure of mouse eye and effect of body position. Curr Eye Res 2003;27(6):355-362. [PubMed: 14704919]

76. Nagaraju M, Saleh M, Porciatti V. Postural changes of IOP and pattern ERG in DBA/2J mice. ARVO. 2007abstract \#211 


\section{A}

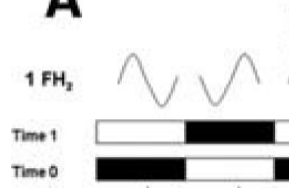

Times

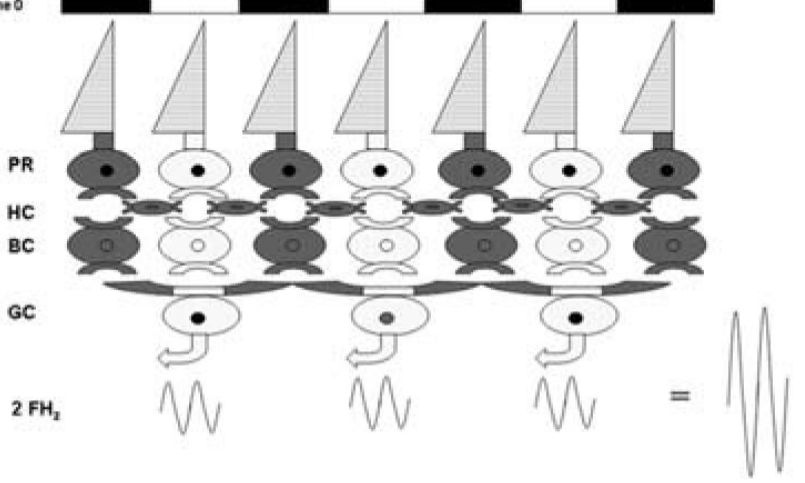

Pattern reversal

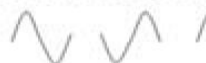
$+$
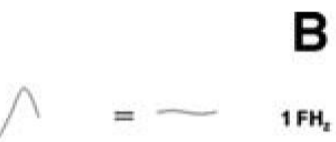

B
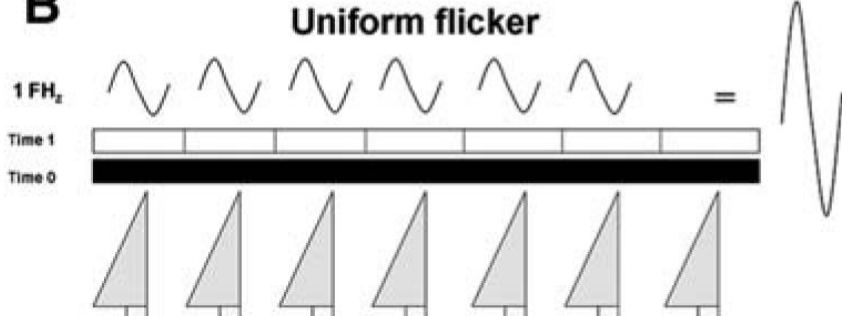

PR

HC

BC

GC

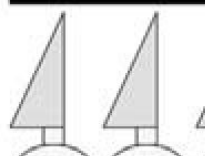

$2 \mathrm{FH}_{2}$
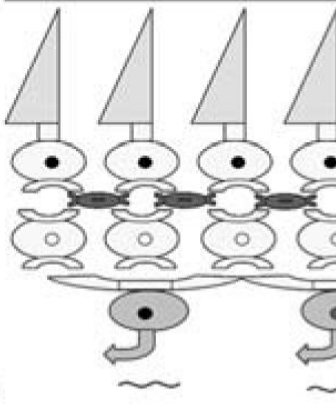

$\sim$
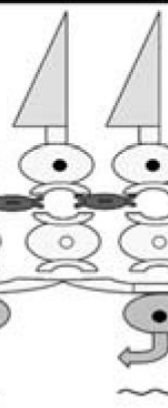

Fig. 1.

Schematic drawing of stimulus modulation and retinal activity during either pattern reversal (A) or uniform flicker (B) For both conditions, stimulus elements alternate (time 0,1) between two conditions of different luminance (darker, lighter). Alternation of a patterned stimulus (A) generates local flicker ERGs, which are $180^{\circ}$ out of phase, so that their summed activity is canceled at the corneal recording electrode. However, pattern elements generate lateral inhibition via horizontal cells; differential center-surround activation of the RGC dendritic field occurs for either period of the pattern-reversal. Local RGC responses are in-phase and sum at the electrode. Alternation of a uniform field (B) generates local flicker ERGs, which are inphase sum at the electrode. Different from pattern-reversal, uniform field flicker generates little differential center-surround activation of the RGC receptive field. Thus, uniform field flicker is dominated by outer retina activity, whereas the PERG is dominated by inner retina activity. Outer retina activity is necessary for the PERG generation but it is not apparent in the PERG waveform because of cancellation at the electrode 


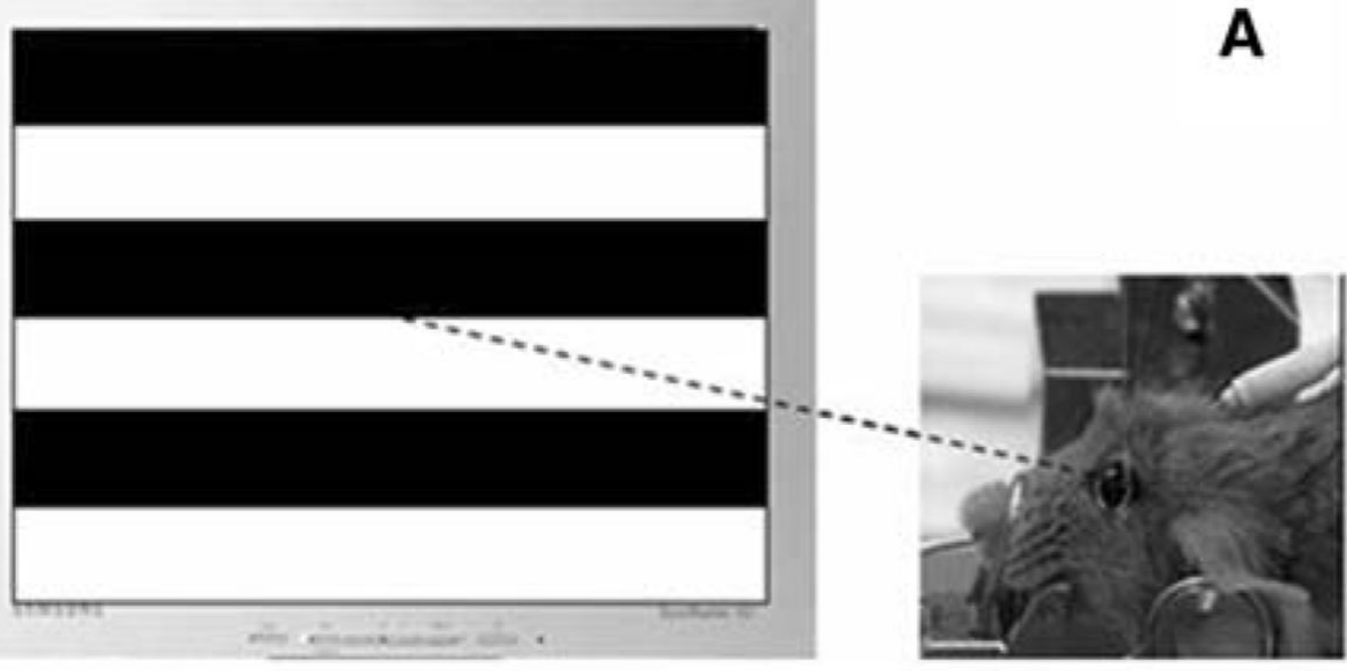

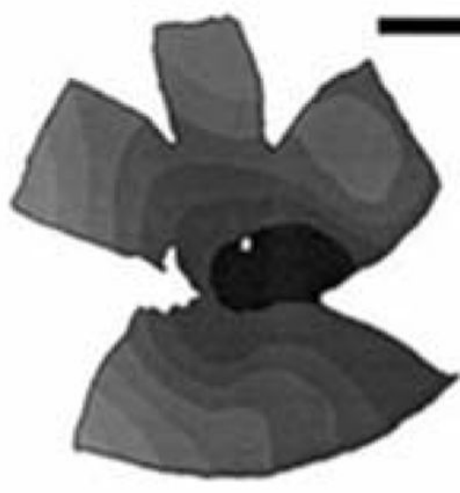

Control

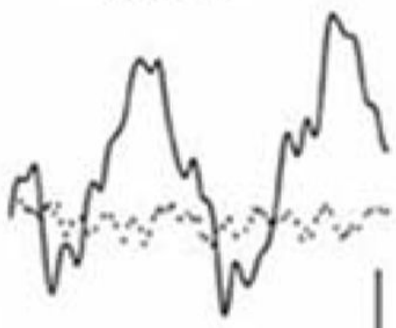

N

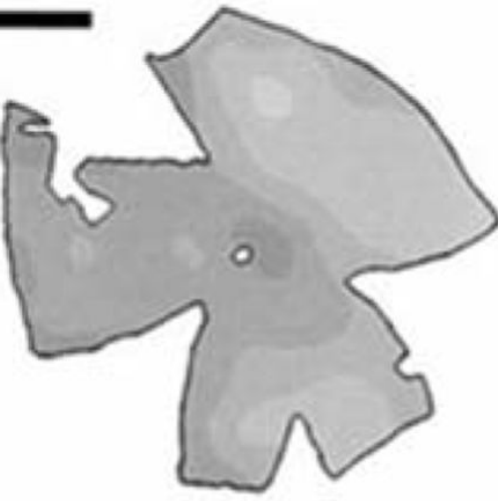

Transected

B

Fig. 2.

(A) the PERG is recorded from anesthetized mice by means of corneal electrodes allowing unobstructed viewing of alternating grating patterns. (B) 2 months after intracranial optic nerve transection in young adult C57BL/6J mice, isodensity maps of cell bodies in the retinal ganglion cell layer of flat mount retinae show massive depletion of neurons and loss of PERG response compared to the control eye. The calibration bars is $3 \mathrm{~mm}$. The label $\mathrm{N}$ indicated the nasal quadrant of each retina. For the PERG, calibration is $0.5 \mu \mathrm{V}$ (vertical) and $100 \mathrm{~ms}$ (horizontal). Modified from refs. [21,27-29] 

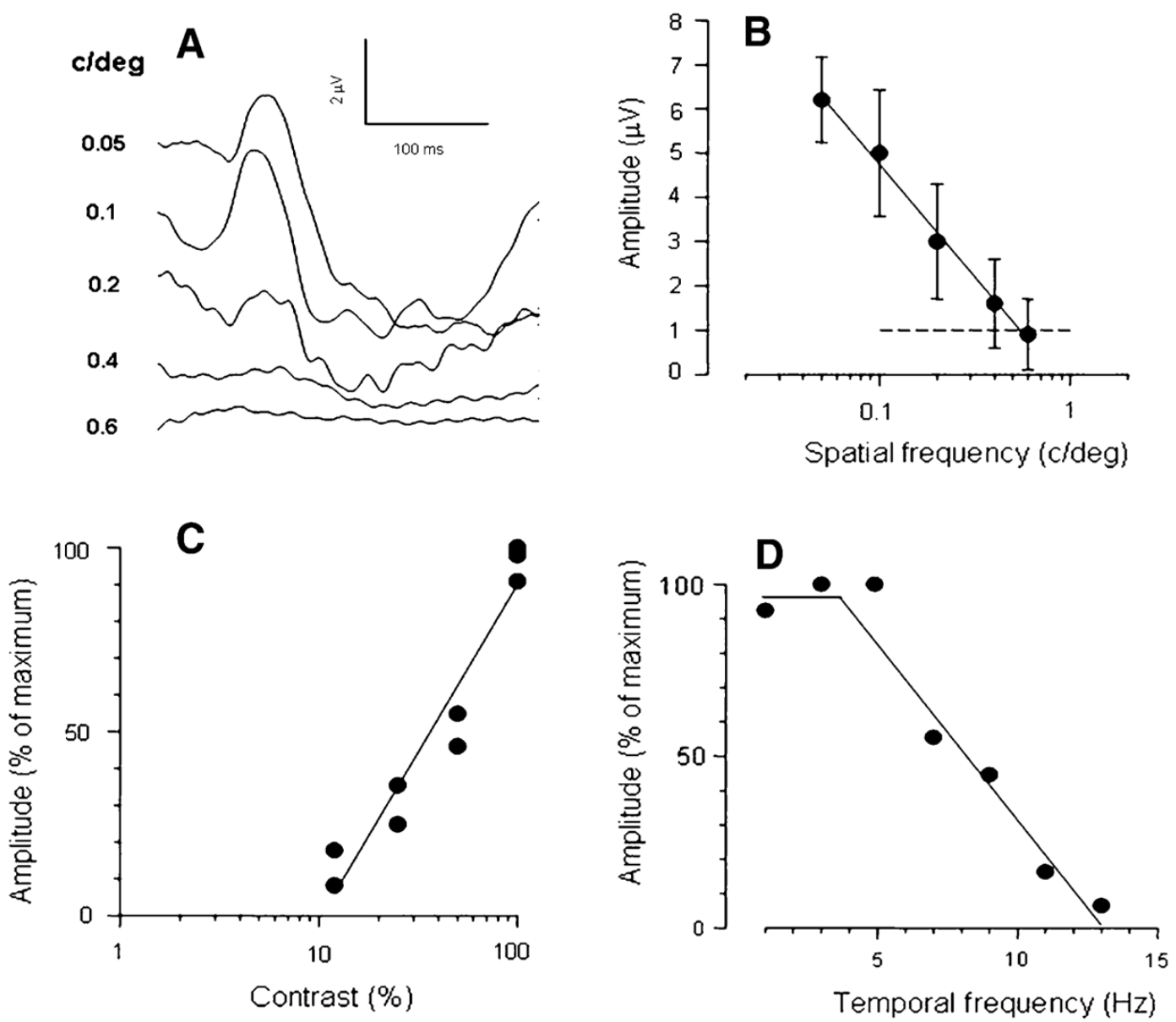

Fig. 3.

Spatial-temporal properties of the mouse PERG. (A) examples of PERG responses recorded in young adult C57BL/6J mice in response to $1 \mathrm{~Hz}$ alternating gratings of high contrast (95\%) and different spatial frequency (numbers to the left of each waveform expressed in cy/deg).

(B) The mean $( \pm$ SEM) PERG amplitude of six different mice decreases with increasing spatial frequency and reaches the noise level (dashed line) at $0.6 \mathrm{cy} / \mathrm{deg}$, which represent the retinal acuity. For gratings of $0.05 \mathrm{cy} / \mathrm{deg}$, the PERG amplitude decreases with decreasing contrast (C) and increasing temporal frequency (D) The contrast threshold is about $10 \%$ and the temporal resolution is about $13 \mathrm{~Hz}$ (26 reversals/s). From ref. [48] 